\title{
Effect of isoflavone (SOY) on histopathology of reproductive organs of rabbits (Oryctolagus cuniculus)
}

\author{
Salma Batool* and Razia Iqbal \\ Department of Zoology, University of Gujrat, Hafiz Hayat Campus, Gujrat-Pakistan \\ *Corresponding author's email: ishanoor500@gmail.com \\ Citation
}

Salma Batool and Razia Iqbal. Effect of isoflavone (SOY) on histopathology of reproductive organs of rabbits (Oryctolagus cuniculus). Pure and Applied Biology. Vol. 9, Issue 1, pp925-935.

http://dx.doi.org/10.19045/bspab.2020.90097

\begin{tabular}{llll}
\hline \hline Received: 08/07/2019 & Revised: 19/11/2019 & Accepted: 23/12/2019 & Online First: 06/01/2020 \\
\hline
\end{tabular}

\section{Abstract}

The main source of isoflavones is soy foods. Soy isoflavones have been extensively studied for its antiestrogenic and estrogenic effects. These exogenous chemicals have less potent effect but there mechanism of action is same as endogenous estrogen. They have adverse effects on histology of testis and ovaries. In present study we evaluate the effect of soy isoflavone on histopathological changes in testis and ovaries. Selected 84 adult rabbits were divided into 8 groups. The dose groups were $(2.5 \mathrm{mg} / \mathrm{kg}$ per body weight= A group), $(3.5 \mathrm{mg} / \mathrm{kg}$ per body weight $=\mathrm{B}$ group), $(5 \mathrm{mg} / \mathrm{kg}$ per body weight $=\mathrm{C}$ group $)$ and control (D) group separately for male and female. The results showed that soy isoflavone have negative effect on reproductive organs and more pronounced effect on male than female. Many histological problems were observed in testis and ovaries. This study shows that soy foods are not good for reproductive health, and use of soy foods in high amount for prolonged time should be prohibited.

Keywords: Histopathological changes; Soy isoflavone; Rabbits; Reproductive hormones;

Reproduction

\section{Introduction}

Isoflavons are natural plant substances which belong to class phytoestrogens [1]. Phytoestrogens are diphenolic yet nonsteroidal compounds that have structural similarity with mammalian estrogen $17-\beta$ estradiol and they have the ability to bind with estrogen receptors ( $a \& \beta)$ [2]. Phytoestrogens consists on more than 100 molecules depending upon their chemical structures into (1) Isoflavones (daidzein, genistein, formonetin, biochanin A), (2) Stilbens (resveratrol), (3) Lignans (secoisolariciresinol- diglucoside, matairesinol), (4) Coumestans (4methoxycoumestrol, coumestrol). Isoflavones mainly present in roots and seeds of 300 different types of plants e.g. extracts of red wine, linseed, red clover, alfalfa. Soybeans (Glycine max L.) are the richest source of isoflavones, and $1 \mathrm{~g}$ dry soybean contains $1.2-4.2 \mathrm{mg}$ of isoflavones. Isoflavones concentration in soybeans depends upon processing, soil, climate and age of maturity [3]. In nature isoflavones present in conjugated form which is biologically inactive form of isoflavones. After ingestion conjugated form of isoflavones change into biologically active form (genistein, daidzein and aglycon) due to hydrolyzation by $\beta$-glicosidases of intestinal bacteria [4]. These phytochemicals have many health related benefits for prevention of cardiovascular diseases, age related (osteoporosis) and hormone dependent conditions (breast and 
prostate cancer). Phytoestrogens have estrogenic as well as anti-estrogenic effects and when they prevent breast cancer it demonstrate its anti-estrogenic effect [5]. In recent years the physiological effects of soy isoflavones extensively studied but public health recommendations of soy isoflavones remain controversial because they have adverse effects on reproduction [6]. Some plants produce phytoestrogen substances which act as endocrine disrupters in insects, mammals, birds and fishes. It was considered that these substances evolved as a defense against herbivores. These substances vary in potency depending upon the environmental conditions, age and species of plant. In Japanese quail testicular weight decreases due to exposure with phytoestrogens. The birds that are exposed with phytoestrogens suffered from infertility decreased reproductive success and differential breeding response. Phytoestrogens has more pronounced effects on male as compared to female reproductive system [7]. In critical developmental stage of rodents, a high dose of phytoestrogens cause temporary infertility, decline sperm quality, altered gonadotropin level and reproductive tract disorders [8].

Earlier studies reported that soy isoflavones have harmful effects on thyroid gland functions. It was reported that Soy isoflavones increase the level of thyroxine (T4) and triiodothyronine (T3) which is the cause of goiter in rodents [9]. The soy isoflavones have beneficial effects on plasma lipoprotein and lipid concentration by significantly reduction in low density lipoprotein (LDL) and very low density lipoprotein (VLDL) in males and females and significantly increase of high density lipoprotein (HDL) in females and less in males [10]. Soy isoflavones have antioxidant properties and genistein is a good and active scavenger of glutathione peroxidase, catalase and superoxide dismutase because in $\mathrm{C}-5$ position it has third hydroxyl group. Genistein has significant effect on protein tyrosine kinase inhibition (PTK). In some brain regions (hippocampus), stomach, prostate and breast cancers PTK are highly expressed. A high dose of isoflavones inhibit PTK and prevent cancer in these tissues. Moreover inhibition of PTK also improves cardiovascular health. Due to the estrogen like properties genistein suppress the arthritis, autoimmune diseases, delayed of type II hypersensitivity and antigen induced asthma [11]. In premenopausal women Soy proteins regulate the menstrual cycle; it delayed the menstruation and increases the length of follicular phase [12]. Isoflavones improve bone health by regulating the Blymphopoiesis and it also reduces bone loss in estrogen deficient females [13]. Due to soy isoflavone the total number of sperm cells and their mobility decreased very significantly. The sperm cells morphology of soymilk treated groups become abnormal and decreased number of leydig and sertoli cells [14]. The lumen of uterine become highly branched and increased the thickness of uterine wall due to glandular epithelium hyperplasia, increase blood supply and connective tissue edema as well as formed new blood vessels [15]. Soy isoflavone decreased in number of corpus luteum and increased atretic follicular count [16].

The main objectives of this research is to determine the effects of Soy isoflavone on histopathological changes in testis and ovaries of rabbit.

\section{Materials and methods \\ Chemical}

Soybeans were obtained from grain market, Railway road, Gujrat, Pakistan.

\section{Selection and handling of rabbits}

This study was conducted on healthy rabbits which were used as experimental animals weighing about $1 \mathrm{~kg}-1.5 \mathrm{~kg}$. Rabbits were allowed to acclimatize the environment for one week before starting the experiment. In this research equal ratio of both male and female rabbits were obtained from Veterinary Research Institute Ghazi Road Lahore. Rabbits were kept in a large room and each group was 
separated by a brick wall. The waste was removed every day to prevent infection and stress. Rabbits had ad labitum access to food and water. Different types of animal colors were put on both sexes for identification in case of any mishap. On the floor of each portion 1 foot soil was spread for healthy environment.

\section{Groups and dosage}

Selected 84 adult rabbits were divided into 8 groups. Three treatment $(\mathrm{A}, \mathrm{B}, \mathrm{C})$ and one control group (D) for female, similarly three treatment $(\mathrm{A}, \mathrm{B}, \mathrm{C})$ and one control group (D) for male. All dose groups of both sexes have three replicates in each group e.g. $(\mathrm{A}=\mathrm{A} 1, \mathrm{~A} 2, \mathrm{~A} 3),(\mathrm{B}=\mathrm{B} 1, \mathrm{~B} 2, \mathrm{~B} 3)$ and $(\mathrm{C}=\mathrm{C} 1, \mathrm{C} 2, \mathrm{C} 3)$. All treatment $(\mathrm{A}, \mathrm{B}, \mathrm{C})$ groups of male and female containing 12 rabbits in each group while control (D) groups of both sexes have 6 rabbits in each group (Table 1). Group name was written on the paper and stick on the wall of each group. Soybeans crushed in powder form and all doses were mixed in soaked bread so that soybean powder stick to bread pieces. Rabbits were given fresh bread, vegetables, Barseem hay (Trifolium alexandrinum) and water.

Table 1. Treatment groups

\begin{tabular}{|c|c|}
\hline Female & Male \\
\hline Group F(A) Low: & Group M(A): \\
$2.5 \mathrm{mg} / \mathrm{kg} \mathrm{B.W}$ & $2.5 \mathrm{mg} / \mathrm{kg} \mathrm{B.W}$ \\
(Low) & (Low) \\
\hline Group F(B): & Group M(B): \\
$3.5 \mathrm{mg} / \mathrm{kg} \mathrm{B.W}$ & $3.5 \mathrm{mg} / \mathrm{kg} \mathrm{B.W}$ \\
(Medium) & (Medium) \\
\hline Group F(C): & Group M(C) 5mg/kg \\
5mg/kg B.W (High) & B.W (High) \\
\hline Group F(D): & Group M(D): \\
Untreated (Control) & Untreated (Control) \\
\hline
\end{tabular}

\section{Histopathology procedure}

To study the histological alteration in ovaries and testis; tissue processing and microtomy was done in Zoology laboratory.

\section{Dissection}

After every 2 weeks pithing of 3 rabbits were occurred from each control group and dose groups of male and female. Rabbits were dissected by following [17] method. After dissection testis and ovaries were removed and washed with water then soaked in $0.085 \%$ saline solution to remove dust, grim and impurities. Then these organs were cut into $3-4 \mathrm{~mm}$ pieces with the help of sterile dissection box for further histopathological studies.

\section{Fixation}

Tissue fixation was the first step of histopathology. Tissues were kept in Bouin's fixative for 7-8 hours; it prevents the decomposition of tissues. Fixation of tissue thickened the cross links between proteins and made impossible to dissolve the protein.

\section{Dehydration of tissue}

This was the second step of histopathology. In this step increasing series of alcohol was used for dehydration of tissues. Tissue were kept in 70\% alcohol for 1-2 hours and then in $95 \%$ alcohol for same time. After that tissues were kept in absolute alcohol for 1 hour.

\section{Washing/Clearing}

Pure xylene was used as a clearing reagent. Xylene has the compatibility for alcohol and paraffin wax. Tissues were kept in Xylene I for 3 hours and then kept in xylene II for same time [18].

\section{Infiltration and tissue embedding}

Paraffin wax was melted at $56^{\circ}$ in wax dispenser. Then wax was poured in to glass tubes and tissues were kept in molten paraffin wax and placed in incubator for overnight.

Paper blocks were made with the help of wooden chuck. Blocks were filled with molten paraffin wax and tissue was placed in center of wax with the help of forceps. When paraffin wax was solidified in blocks then blocks were transferred to cool bowel of water and then placed in refrigerator for 12 hours.

\section{Wax block trimming and mounting}

Trimmed the excess paraffin wax from all sides of block with the help of sharp knife that only $5-6 \mathrm{~mm}$ wax was left on each side of block. For mounting the block on wooden chuck trimmed wax block was 
melted from one side with the help of flame on attach with chuck then chuck was placed in chuck holder of rotary microtome machine [19].

\section{Turn on water bath}

Water bath was turned on and set temperature at $37-39^{\circ} \mathrm{C}[20]$.

\section{Sectioning}

Tissue sectioning and slide preparation was done by microtome. knife was placed into knife holder; set proper cutting angle and securely tightened the knife. Wheel of microtome was in locked position. Then cut the sections carefully having diameter 57 microns. Grasp the beginning of section with the help of camel hair brush and gently life up from knife and slowly lay the tissue section on tissue floating bath. It removes the wrinkles in ribbon of tissue section.

Mounting the sections on glass slides Use cleaned glass slides and labeled the slide with accession number as was on the cutting block. Mayer's albumen was applied on glass slide for adhesion of tissue section then inserts the glass slide in water bath perpendicularly and centrally orients the sections on slide and then carefully lifts the slide from water. Glass slides were dried at room temperature for 8-10 hours.

\section{Staining}

\section{Deparaffinized the tissues}

The first step of staining was dewaxing of tissues by kept the slides in pure xylene for 2-3 min.

\section{Rehydration}

The slides were passed through downward series of alcohol and then rehydrate by passing through alcohol. In each downward series of alcohol slides were kept for $5 \mathrm{~min}$.

\section{Hematoxylin and eosin staining}

For hematoxylin staining slides were kept in hematoxylin stain for 2 min and after that washed with running water for $5 \mathrm{~min}$. For discoloration of excessive stain passed it through $70 \%$ alcohol for $2 \mathrm{~min}$ and $90 \%$ alcohol for $3 \mathrm{~min}$.

For eosin staining slides were kept in eosin stain for $2 \mathrm{~min}$. For removing excess stain slides were passed thorough 90\% alcohol for $2 \mathrm{~min}$ and then absolute alcohol for 2 $\min$.

\section{Lubrication of tissues}

For lubrication of tissues; slides were dipped in cedar wood oil for $1 \mathrm{~min}$.

\section{Clearing of tissues}

For clearing the cedar wood oil, slides were dipped in Xylene for 2-3 sec.

\section{Mounting the cover slips}

Put the Canada balsam on tissues and then carefully placed the coverslips. Slides were allowed to dry before observing in the microscope.

\section{Slides observation}

Slides were kept in germ free environment and carefully observe the alterations in tissues of testis and ovaries thorough the light microscope attached with digital camera [18].

\section{Results}

The findings of the present study revealed that soy isoflavone cause multiple reproductive abnormalities in adult male and female rabbits. Male rabbits were more affected as compared to female rabbits. When soy isoflavone was gave to experimental rabbits it was observed that ovaries weight significantly increased in females and testis weight was significantly decreased in male rabbits. The FCR was also decreased in soy treated groups as compared to control groups. The histological alterations were also observed in ovaries and testis in this study. The reproductive hormones (Estrogen, progesterone \& testosterone) in dose groups were also compared to control group. There was significant difference was observed in sex hormonal level of dose and control groups. According to [21] lower level of soy isoflavone have not adverse effect on reproductive parameters but high dose of soy isoflavone adversely affect the reproductive organs and sex hormonal level.

\section{Histopathology results}

Histological changes in testis and ovaries were confirmed by the comparison of soy treated and control groups at $15^{\text {th }}, 30^{\text {th }}$ and $45^{\text {th }}$ days. Histological studies were showed 
the tissue necrosis, sertoli cell damaged, hemorrhage, cysts and tumors in tissue of ovaries and testis (Figs. 1-7).

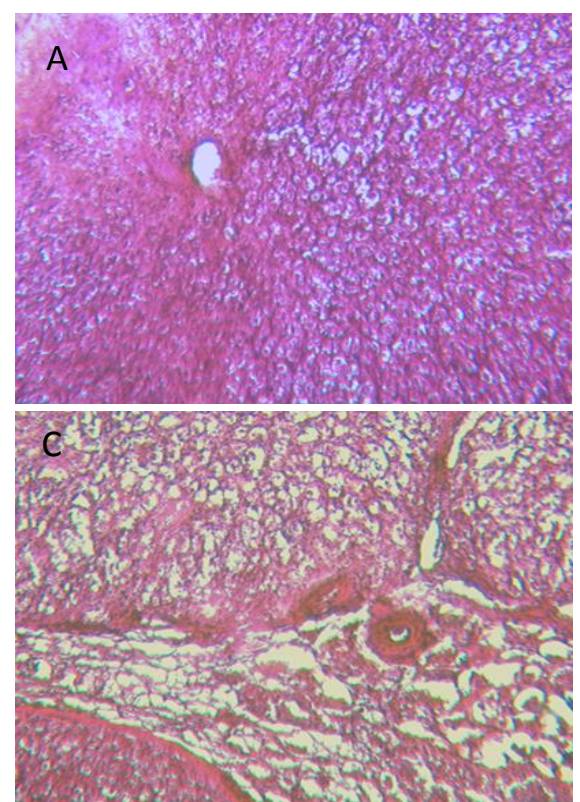

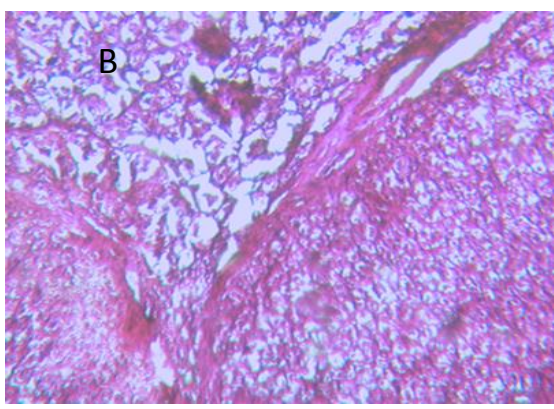

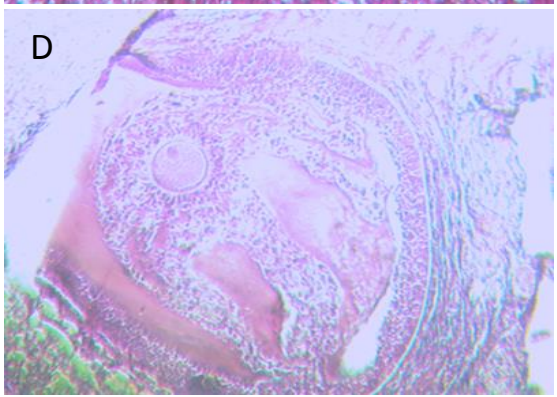

Figure 1. Shows comparison of effects of soy isoflavone on ovaries between dose group A (Low), B (medium), C (High) and control D group at 10X magnification power under light microscope at $15^{\text {th }}$ day. There were no histological alterations seen in these groups
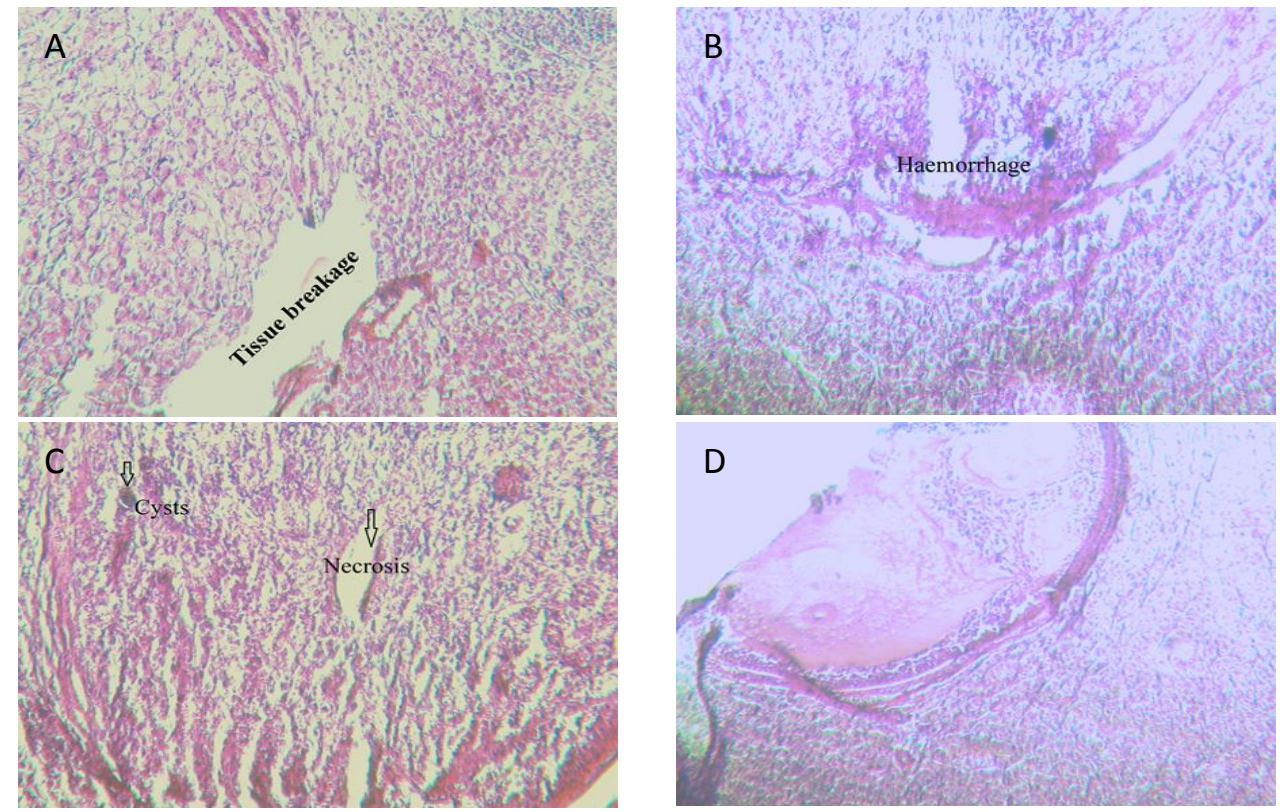

Figure 2. Shows comparison of effects of soy isoflavone on ovaries between dose group A (Low), B (medium), $C$ (High) and control D group at 10X magnification power under light microscope at $30^{\text {th }}$ day. The histological studies showed that there was tissue damaged in low dose group, haemorrhage in medium dose group and cysts and tissue necrosis in high dose groups at day $30^{\text {th }}$ 

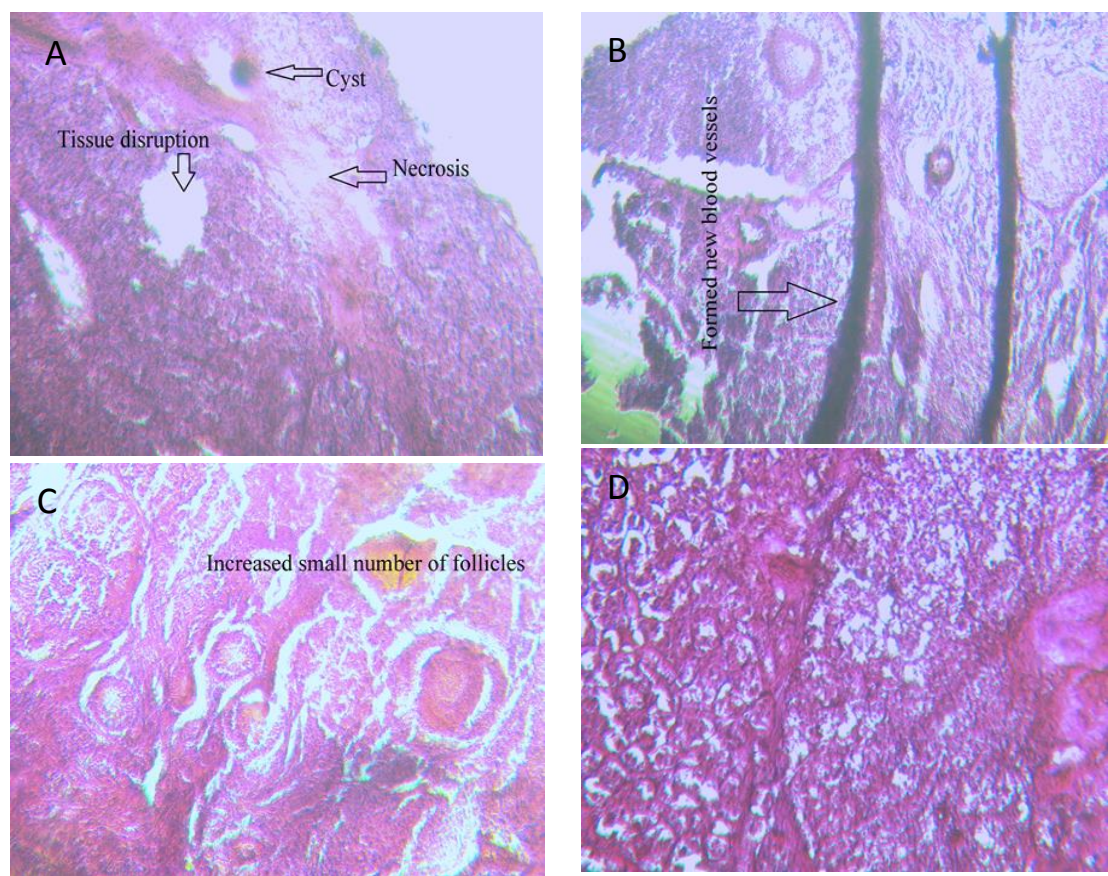

Figure 3. Shows comparison of effects of soy isoflavone on ovaries between dose group A (Low), B (medium), C (High) and control D group at 10X magnification power under light microscope at $45^{\text {th }}$ day. The histological studies showed that there was tissue disruption, cyst formation and tissue necrosis in low dose group (A), tissue damaged in medium dose group (B) and increased number of small follicles in high dose group (C) at day $45^{\text {th }}$
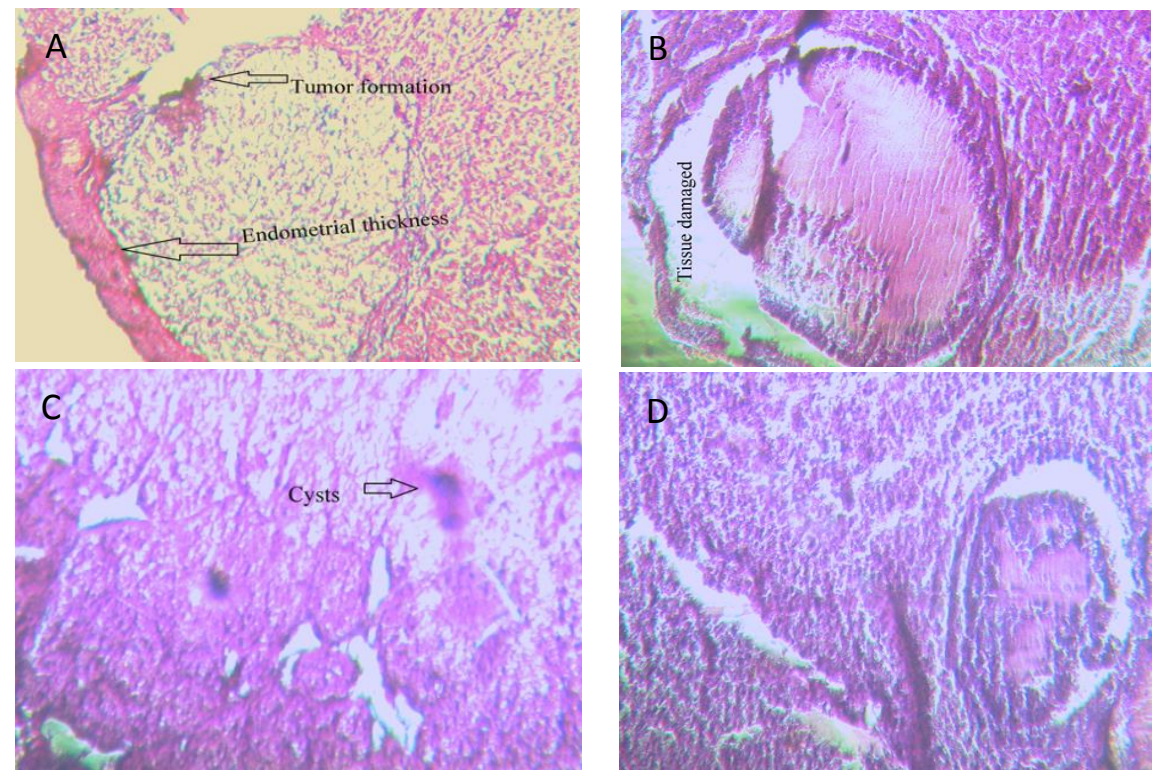

Figure 4. Shows comparison of effects of soy isoflavone on ovaries between dose group A (Low), B (medium), C (High) and control D group at 10X magnification power under light microscope at $6^{\text {th }}$ day. The histological studies showed that there was tumor formation and epihtelial thickness in low dose group (A), formed new blood vessels in medium dose group (B) and cysts formation in high dose group (C) at day $60^{\text {th }}$ 

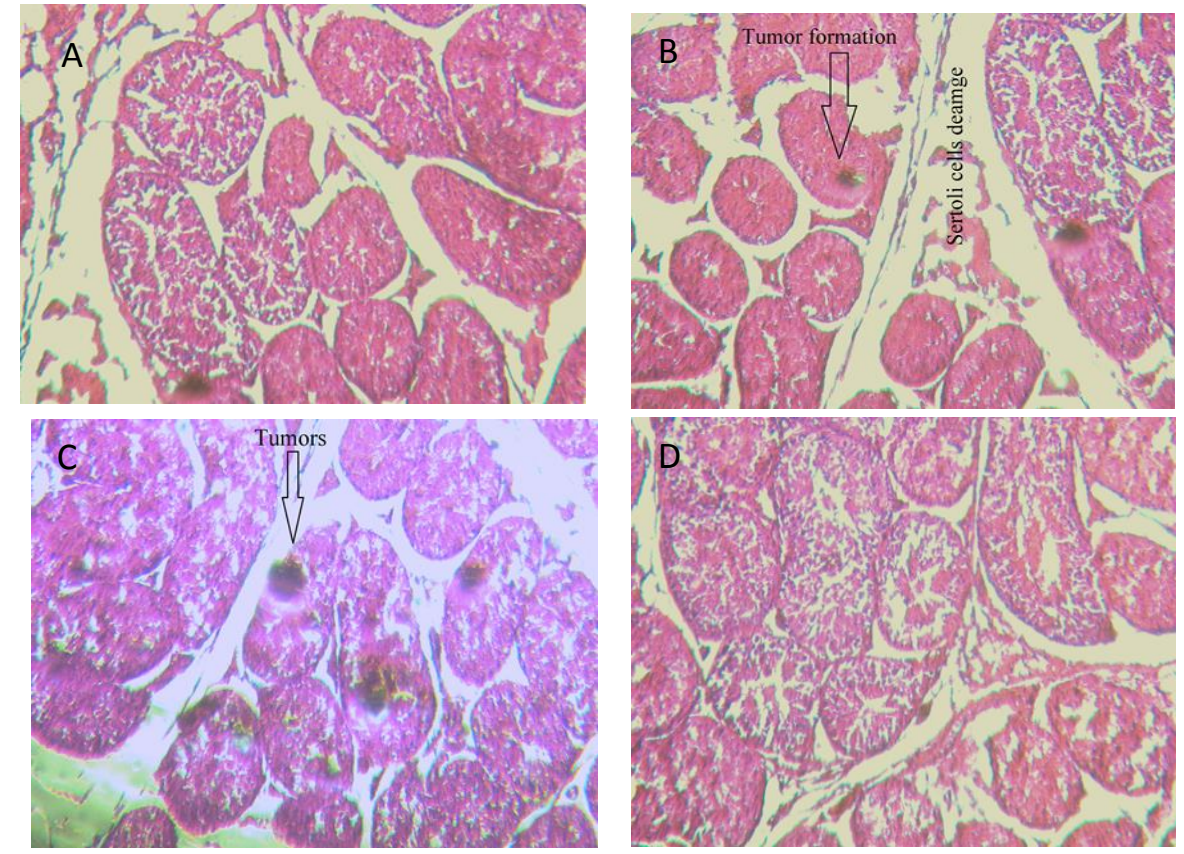

Figure 5. Shows comparison of effects of soy isoflavone on testis between dose group A (Low), B (medium), C (High) and control D group at 10X magnification power under light microscope at $15^{\text {th }}$ day. The histological studies showed that there was normal histology in low dose group (A), sertoli cells damage and tumor formation in medium dose group (B) sertoli cells damge and tumor formation was more formation in high dose group $(C)$ at day $15^{\text {th }}$
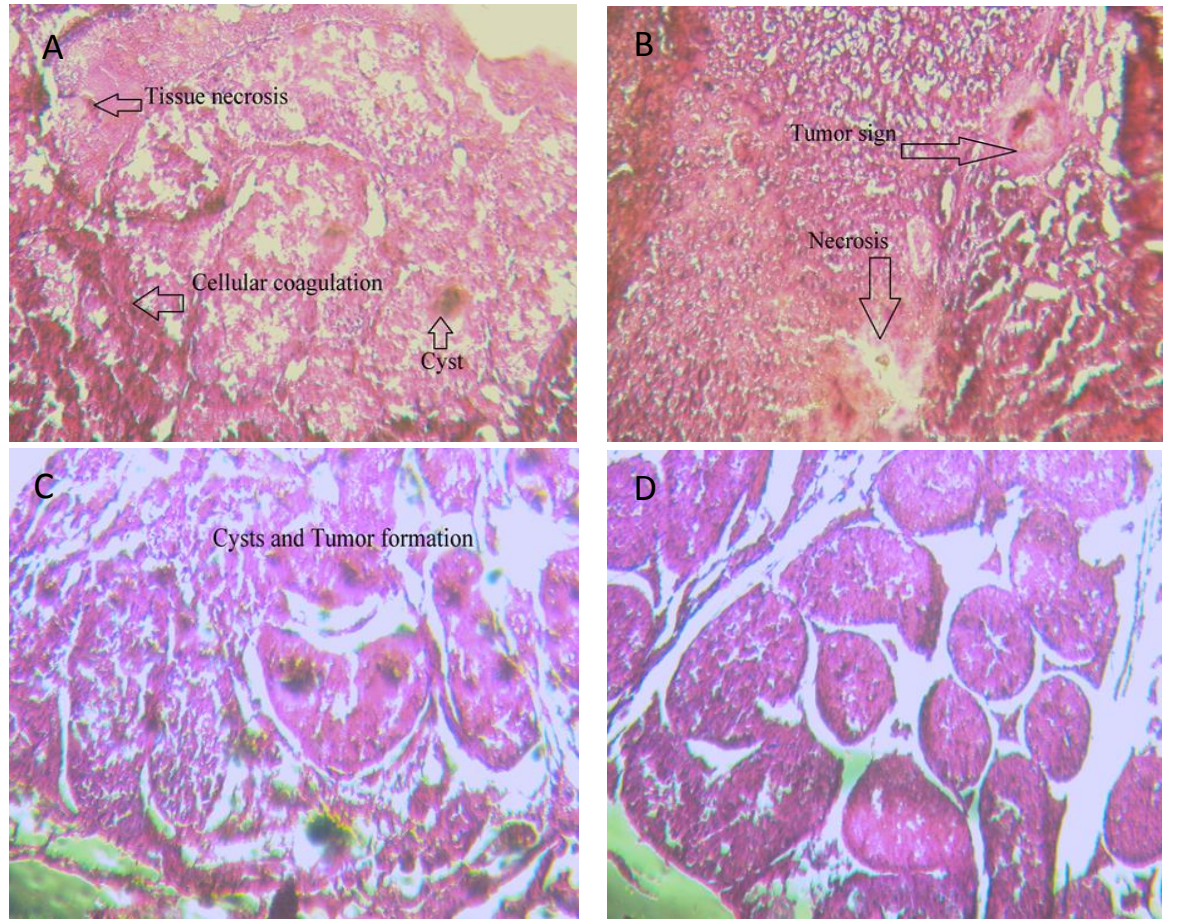

Figure 6. Shows comparison of effects of soy isoflavone on testis between dose group A (Low), B (medium), C (High) and control D group at 10X magnification power under light microscope at $3^{\text {th }}$ day. The histological studies showed that there was tissue necrosis, cysts formation and cellular coagulation in low dose group (A), there was tumor sign and necrosis in medium dose group (B) sertoli cell damage, cysts and tumor formation was more in high dose group (C) at day $30^{\text {th }}$ 

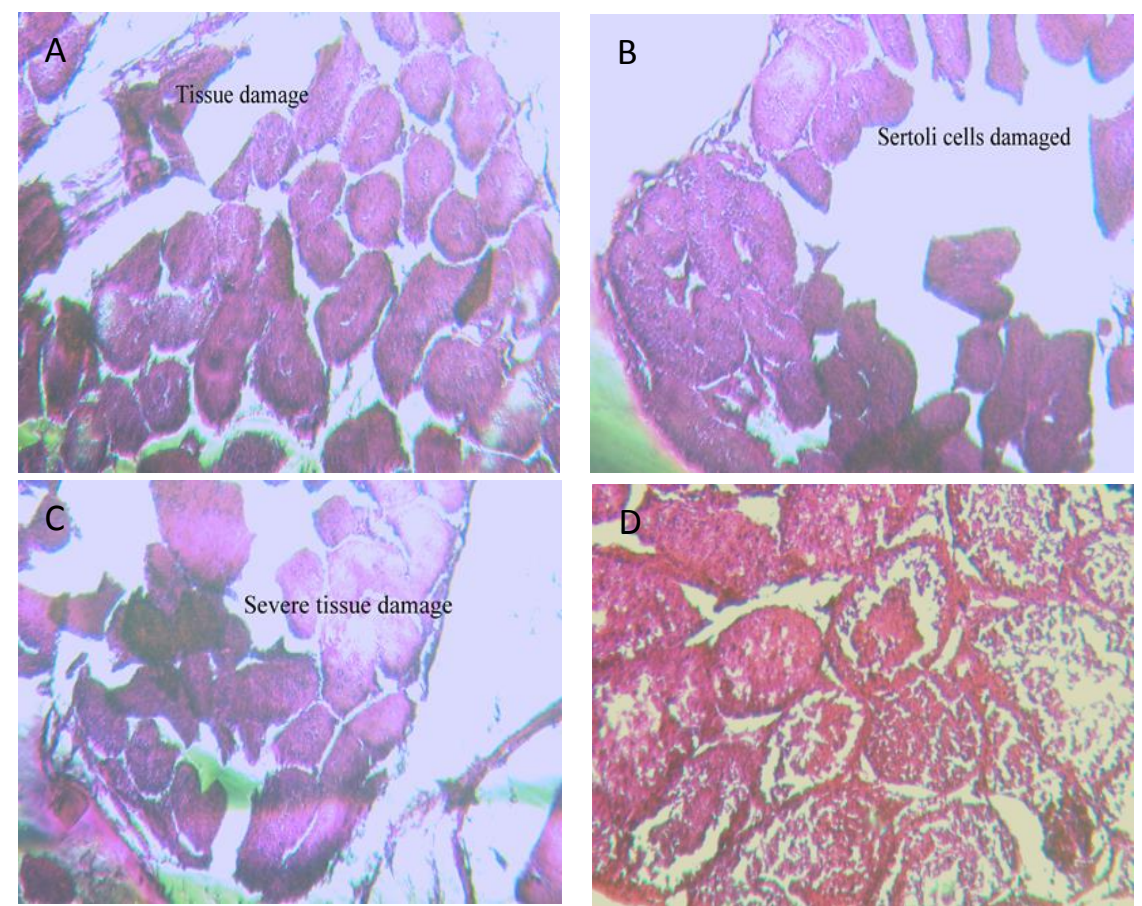

Figure 7. Shows comparison of effects of soy isoflavone on testis between dose group A (Low), B (medium), $\mathrm{C}$ (High) and control D group at 10X magnification power under light microscope at $45^{\text {th }}$ day. The histological studies showed that there was tissue damage, in low dose group (A), there was sertoli cells damage medium dose group (B), and severe tissue and sertoli cells damage sertoli cell damage in high dose group (C) at day $45^{\text {th }}$

\section{Disscussion}

In mammals the reproductive organs are very sensitive to exogenous chemicals. In recent years there was a decrease in quality and quantity of male sex cells. There are many types of exogenous compounds like pesticides, drugs, xenohormones, phytoestrogens etc. In current years large number of population exposed to phytoestrogen and soybeans are main source of phytoestrogens. In soybeans, isoflavones are the most studied component; but their effect on reproductive organs is not fully understood. Their effects on non rodent species is remain to be determined. In this study we used equal ratio of male and female rabbits to determine the effect of soy isoflavone on testicular and ovarian tissues. The results showed that the low dose concentration of soy isoflavone have not serious effects, while high dose concentraion have severe damaging effects on tissues of testis and ovaries. Our results were consistant with the findings of [14]. In this study 4 weeks old 24 male Swiss mice were used to determine the effect of soymilk on male fertility. Duration of this experiment was 90 days, and animals were divided into four groups. Group A containing 6 mice from a nursing mother who fed soy and received milk for 90 days., Group B containing 6 mice from a nursing mother who fed soy and receiving plugs and water for 90 days., Group C containing 6 mice from a female witness and who received soybeans for 90 days, Group D containing 6 mice received plugs and water during the entire experimental period. After every one week blood was taken before sacrifice the mice and blood test were performed for testosterone. Then epididymis, testis and seminal vesicles were separated from body and weighed. Sperm cells morphology and mobility were also studied. The total number of sperm cells and their mobility were decreased significantly. The sperm cells morphology of soymilk treated groups was abnormal [14]. 
In 2008 one study was performed on man, 99 males were selected who consumed soy based diet for three months. The results showed that sperm concentration was inversally related to soy diet. It was concluded that soy foods have deleterious effects on male fertility [22]. Our results were also according to this study.

In another study male Sprague-Dawley rats were feeding for three weeks with $17 \beta$ estradiol, bisphenol A and soy diet to determine their effects on hormones level and reproductive organs. After three weeks the histological differences were recognized in testis of all treated groups. The soy extract and bisphenol A treated groups showed damage, absence of mature spermatids, absence of lumen, sloughing of the germ cells and cellular debris in the seminiferous tubules [23]. The results of our study consistant with the results of Norazit et al. [23].

In another study 30, 60 and 90gm cooked soybeans were given to male and female albino rats for three months and determine their effect on fertility. The histology studies showed that soybean diet decreased the ovarian follicles, cause cystic hyperplasia and endometrial thickness. Spermatogenesis arrest and leydig cells decreased in number [24]. The results of our study were also in favor of this study.

Our results were consistent with Zin et al. [16] who determine the effect of genistein on reproductive system of female Sprague Dawley rats, 18 rats divided into three groups, each group consist of 6 rats. One is the control group and other two groups were treated with $10 \mathrm{mg} / \mathrm{kg} / \mathrm{BW}$ and $100 \mathrm{mg} / \mathrm{kg} / \mathrm{BW}$ from $22-42$ postnatal day. In $10 \mathrm{mg} / \mathrm{kg}$ BW there were decreased in uterus, ovary and body weight and reverse in $100 \mathrm{mg} / \mathrm{kg} \mathrm{BW}$. This study showed that there was decreased in number of corpus luteum and increased atretic follicular count [16].

The results are also in conformity with Modaresi et al. [25] who reported that high dose of soybeans elevate the testosterone level and decrease the sperm count in male mice. Three types of soy doses $(20,30$ and $50 \%$ ) were given to male mice for 8 weeks. Results showed that sperm count decreased in all soy treated groups.

According to Adesanya et al. [26] three diets $(0 \%, 10 \%$ and $20 \% \mathrm{~W}: \mathrm{W})$ of raw soy flour were given to male Wister rats for 8 weeks. Results showed that there was a significant decrease in seminal vesicle, prostate gland and testis weight as compared to control group. In all treated groups testosterone level and sperm count were also significantly decreased. The results were accordance with this study.

\section{Conclusion and recommendations}

This study shows that soy isoflavone have damaging effects on testis and ovaries of rabbits. It cause many histological problems as well as change the hormonal level in soy treated groups. We can use the soy isoflavone in case of low level of natural estrogen in our body but the use of these exogenous compounds should be concerned as they may cause many problems. Soy isoflavones have more pronounced effects on male rabbits. This study also shows that soy isoflavone have cancer promoting effect on reproductive tissues. The specific dose of soy isoflavone which enhance fertility yet not identified. Soy products have seriously negative effects on reproduction when they use for prolong time in high amount.

Soy beans and soy products have adverse effects on male and female reproductive system. So food and agriculture organization should be reevaluating its benefits in our daily life. Prolonged use of soy products in high amount should be discouraged. Further studies should be needed by changing the model organism as well as dose concentration because soy isoflavone effects vary according to animal species and dose concentration.

\section{Author's contributions}

Conceived and designed the experiments: $S$ Batool \& R Iqbal, Performed the experiments: S Batool, Analyzed the data: S Batool \& R Iqbal, Contributed reagents/ 
materials/ analysis tools: S Batool \& R Iqbal, Wrote the paper: S Batool.

\section{References}

1. Vitale DC, Piazza C, Melilli B, Drago F \& Salomone S (2013). Isoflavones: estrogenic activity, biological effect and bioavailability. Eur J 38: 15-25.

2. Marquez SR, Hernandez H, Flores JA, Gutiérrez MM, Duarte G, Vielma J, Rodriguez GF, Fernandez IG, Keller M \& Delgadillo JA (2012). Effects of phytoestrogens on mammalian reproductive physiology. Tropi and Subtropical Agroecosys 15: 129-145.

3. Pilsakova L, Riecansky I \& Jagla $F$ (2010). The Physiological Actions of Isoflavone Phytoestrogens. Physiol Res 59: 651-664.

4. Aguair PM \& Barbosa ADP (2014). Use of soy isoflavone on hormone replacement therapy during climacteric. African J of Pharm and Pharmacol 42: 1071-1078.

5. Weber KS, Setchell KDR, Stocco DM \& Lephart ED (2001). Dietary soyphytoestrogens decrease testosterone levels and prostate weight without altering $\mathrm{LH}$, prostate 5-reductase or testicular steroidogenic acute regulatory peptide levels in adult male Sprague-Dawley rats. $J$ of Endocrinol 170: 591-599.

6. Wood CE, Appt SE, Clarkson TB, Franke AA, Lees CJ, Doerge DR \& Cline JM (2006). Effects of High-Dose Soy Isoflavones and Equol on Reproductive Tissues in Female Cynomolgus Monkeys. Biol of Reprod 75: 477-486.

7. Norris DO \& lopes KH (2011). Hormones and reproduction of vertebrates Elsevier.

8. Mitchell GH, Cawood A, Kinniburgh D, Provan A, Andrew R, Collins AR \& Irvine DS (2001). Effect of a phytoestrogen food supplement on reproductive health in normal males. Clin Sci 100: 613-618.

9. Mittal N, Hota D, Dutta P, Bhansali A, Suri V, Aggarwal N, Marwah RK \&
Chakrabarti A (2011). Evaluation of effect of isoflavone on thyroid economy \& autoimmunity in oophorectomised women: a randomised, double-blind, placebocontrolled trial. Indian J Med Res 133: 633-640.

10. Anthony MS, Clarkson TB, Hughes CL, Morgan TM \& Baoerk GL (1995). Soybean Isoflavones Improve Cardiovascular Risk Factors without Affecting the Reproductive System of Peripubertal Rhesus Monkeys. The J of Nutri, pp 43-50.

11. Ishimi $Y$, Miyaura $C$, Ohmura $M$, Onoe Y, Sato Y, Uchiyama Y, Ito M, Wang, X, Suda T \& Ikegami S (1998). Selective Effects of Genistein, a Soybean Isoflavone, on BLymphopoiesis and Bone Loss Caused by Estrogen Deficiency. Endocrinol 140: 1893-1900.

12. Cassidv A, Bingham $S$ \& Setchell KD (1994). Biological effects of a diet of soy protein rich in isoflavones on the menstrual cycle of premenopausal women. Am J Clin Nutr 60: 333-340.

13. Ishimi $Y$, Miyaura $C$, Ohmura $M$, Onoe Y, Sato Y, Uchiyama Y, Ito M, Wang, X, Suda T \& Ikegami S (1998). Selective Effects of Genistein, a Soybean Isoflavone, on BLymphopoiesis and Bone Loss Caused by Estrogen Deficiency. Endocrinol 140: 1893-1900.

14. Zeriouh IF, Addou S, Bouferkas Y, Kheroua O \& Saidi D (2014). Effect of the consumption of milk of soya on the male fertility of swiss mice. Inter $J$ of Pharmacy and Pharma Sci 4: 669-676.

15. Helmy SA, Emarah HA \& Abdelrazek HMA (2014). Estrogenic Effect of Soy Phytoestrogens on the Uterus of Ovariectomized Female Rats. Clinic Pharmacol Biopharmaceut 2: 1-7.

16. Zin SM, Omar SZ, Khan NLA, Musameh NI, Das N \& Kassim NM (2013). Effects of the phytoestrogen genistein on the development of the 
reproductive system of Sprague Dawley rats. Clinics 68: 253-262.

17. Hau J, and Hoosier JR (2003). Handbook of Laboratory Animal Science, 2nd Edition, Animal Models, CRC Press, Boca Raton, pp 1-9.

18. Dury RAB \& Wallington EA (1980). In Carleton Histological Techniques. Oxford New York Toronto Oxford Uni Press 5: 40-67.

19. Bancroft JD \& Stevens A (1990). Theory and practice of histological techniques ed.3, Churchill livingstoneinc. Edinburgh. London, Melbourne and New York.

20. Ganjali H (2010). Tissue processing: An Overview. Annals of Biol Res 3: 5374-5378.

21. Yuan XX, Zhang B, Li LL, Xiao CW, Fan JX, Geng MM \& Yin YL (2012). Effects of soybean isoflavones on reproductive parameters in Chinese mini-pig boars. J Anim Sci Biotechnol 3: 31 .

22. Chavarro JE, Toth TT, Sadio SM \& Hauser R (2008). Soy food and isoflavone intake in relation to semen quality parameters among men from an infertility clinic. Hum Reprod 23: 2584-2590.

23. Norazit A, Mohamad J, Razak SA, Abdulla MA, Azmil A \& Mohd MA (2012). Effects of Soya Bean Extract, Bisphenol A and $17 \beta$-Estradiol on the Testis and Circulating Levels of Testosterone and Estradiol Among Peripubertal Juvenile Male SpragueDawley Rats. Sains Malaysiana 41: 63.

24. Din SE, Batta H, Azim AE \& Fattah AE (2011). Effect of soybean on fertility of male and female albino rats. J of American Sci 7: 872-883.

25. Modaresi M, Messripour M \& Khorami H (2011). Effect of soybean on male reproductive physiology in mice. Inter Conf on Life Sci and Technol 3: 15-18.

26. Adesanya OA, Oyesola OA, Adesanya RA, Bamitale KDS \& Odubela OO (2016). Effects of Soy-flour Enriched Diet on the Testis and Gonadal Hormone Status of Male Wistar Rats. Sch J App Med Sci 4: 1657-1661. 